\title{
Plasma Brain-Derived Neurotrophic Factor as a Peripheral Marker for the Action Mechanism of Antidepressants
}

\author{
Hwa-Young Lee ${ }^{a}$ Yong-Ku Kim ${ }^{b, c}$

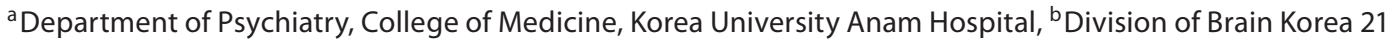 \\ Biomedical Science, Korea University, Seoul, and ' Department of Psychiatry, College of Medicine, Korea University \\ Ansan Hospital, Ansan, Korea
}

\section{Key Words}

Brain-derived neurotrophic factor • Major depressive

disorder $\cdot$ Antidepressant treatment

\begin{abstract}
Numerous studies have demonstrated that depression is associated with a decreased expression of brain-derived neurotrophic factor (BDNF). BDNF shows antidepressant-like effects in animal models. Therefore, we tested the hypothesis that BDNF might be a peripheral marker for the mechanism of action of antidepressant agents in humans. Thirty-two patients meeting the DSM-IV criteria for major depressive disorder and 50 normal control subjects were recruited for this study. Plasma BDNF levels and Hamilton Depression Rating Scales were measured at baseline and 6 weeks after antidepressant administration. At baseline, the mean plasma BDNF level was lower in the depressive patients (698.1 $\pm 537.7 \mathrm{pg} /$ $\mathrm{ml})$ than in the control subjects $(830.7 \pm 624.8 \mathrm{pg} / \mathrm{ml})$, although the difference was not statistically significant $(p=$ 0.33). The plasma BDNF levels in depressive patients significantly increased from $698.1 \pm 537.7$ to $1,028.9 \pm 744.5$ after 6 weeks of antidepressant treatment $(p=0.01)$. Moreover, plasma BDNF levels were significantly increased after 6 weeks of treatment in the responder group, while there was no statistically significant change in the unresponsive group. These results suggest that the therapeutic response after antidepressant administration might be attributable to the in-
\end{abstract}

crease in BDNF levels. BDNF may play a critical role in the action mechanism of antidepressant drugs. Further studies with a larger number of subjects are needed to verify these findings.

Copyright $\odot 2008$ S. Karger AG, Basel

\section{Introduction}

Brain-derived neurotrophic factor (BDNF), an important member of the neurotrophin family, is abundant in the brain and peripheral nervous system. It has many effects on the nervous system, such as neuronal growth, differentiation, and repair [1].

It has been shown that stress decreases the synthesis of hippocampal BDNF in adult animals [2,3] and induces atrophy of the apical dendrites of CA3 neurons [4-6]. Growing evidence suggests that BDNF may play a crucial role in mental disorders such as Alzheimer's disease [7], schizophrenia [8,9], and especially depression [10-13]. So far, considerable work on the involvement of neurotrophic factors in the pathophysiology of depression has been carried out. Direct infusion of BDNF into the rat midbrain has antidepressant effects in the learned helplessness and forced swim behavioral models of depression in rodents [12]. In addition, long-term antidepressant drug treatment and electroconvulsive therapy can increase BDNF expression [14]. 
Although recent decades have witnessed a tremendous revolution in the development of antidepressant drugs, the neurochemical effects that underlie the therapeutic action of these agents remain largely unknown. Antidepressant drugs acutely increase levels of monoamines, but it takes $2-3$ weeks to show a clinical response after the administration of an antidepressant drug [15], and the initial response rate in patients with major depressive disorders is about $70 \%$ [16]. These observations suggest that alterations in monoamine metabolism alone cannot explain the entire antidepressant effect. In this respect, it was suggested that the mechanism of action might be associated with intracellular signal transduction pathways that are linked to the expression of specific genes [17]. The neural plasticity hypothesis proposes that depression results from an inability to make appropriate adaptive responses to stress [18]. By stimulating intracellular pathways, antidepressants lead to upregulation of cAMP response element-binding (CREB) protein and an increase in the expression of neurotrophic factors, particularly BDNF. Based on the neuroplasticity hypothesis, plasma BDNF levels are necessarily increased by antidepressant action. The increase in BDNF by antidepressant treatment has been confirmed by a number of studies from many different laboratories. There have been, however, some inconsistent reports with certain classes of antidepressants, dosages of antidepressants, and the time of measurement after antidepressant administration $[19,20]$. Moreover, most previous studies were performed to measure changes in BDNF levels after antidepressant administration, but without subdividing the patients according to responsiveness. In this study, therefore, we aimed to determine whether there is a difference in the change of BDNF levels between responsive and unresponsive patients before and after antidepressant administration.

\section{Methods}

\section{Subjects}

Thirty-two patients diagnosed with a major depressive disorder according to DSM-IV criteria were recruited from patients who visited Korea University Medical Center Ansan Hospital between March 2002 and July 2005. None of the depressive patients had taken psychotropic medications within the previous 2 weeks. During the study, concomitant medications such as benzodiazepine were permitted. Three of the depressive patients had attempted suicide at the time of their diagnosis. The control subjects consisted of 50 randomly selected healthy individuals who visited Korea University Ansan hospital for regular health screenings. The control subjects were closely matched with the depres- sive patient group in terms of age and sex. Control subjects were excluded if they had any self-reported personal or familial psychiatric history or psychotropic medication history, or if they had scores $\geq 10$ on the Beck Depression Inventory or $\geq 40$ on the State-Trait Anxiety Inventory. The study protocol was approved by the Ethics Committee of Korea University, and written informed consent was obtained from all patients and control subjects.

\section{Clinical Evaluation}

The severity of depressive symptoms was also evaluated using Hamilton's 17-item depression rating scale [21]. Individuals were evaluated independently by 2 trained psychiatrists. The evaluations consisted of reviews of psychiatric and medical histories, evaluations of current and previous medication and alcohol intakes, and semi-structured interviews for the purpose of establishing DSM-IV criteria diagnosis. Because BDNF expression in the central nervous system is modified in diabetes mellitus, epilepsy, addiction disorders, and eating disorders, patients with these diseases were excluded from this study.

Diagnoses and ratings were decided by mutual consent (blind to plasma BDNF levels).

In the present study, various antidepressants were used according to the patient's symptoms and tolerance, including paroxetine (7 patients, average dose: $28.6 \mathrm{mg}$ ), citalopram (16 patients, average dose: $30.6 \mathrm{mg}$ ), and venlafaxine (10 patients, average dose: $150.0 \mathrm{mg}$ ).

To group the patients by responsiveness, responders were defined as those patients who had a decrease of at least $50 \%$ in their HDRS total score between baseline and 6 weeks after antidepressant treatment.

\section{Blood Sample Collection}

For depressive patients and control subjects, blood samples were drawn from the subjects' antecubital veins at the same time of the morning following an overnight fast. Approximately $10 \mathrm{ml}$ of blood was collected and placed in a lithium heparin vacuum tube.

\section{Plasma BDNF Measurement}

All blood samples were immediately centrifuged at 3,800 rpm for $10 \mathrm{~min}$. Plasma was stored at $-70^{\circ} \mathrm{C}$ until it was thawed for assay. Human BDNF was assayed by using the DuoSet ELISA Development System (R\&D Systems, cat No. DY248). All assays were performed in duplicate using the manufacturer's recommended buffers, diluents, and substrates. In brief, the capture antibody was diluted to the final concentration $(2 \mu \mathrm{g} / \mathrm{ml})$ in phosphatebuffered saline (PBS), and $100 \mu$ l of diluted capture antibody was immediately put into a 96 -well plate. The plate was sealed and incubated overnight at room temperature. The next morning, the wells were washed 3 times with $400 \mu \mathrm{l} /$ well of PBS containing $0.05 \%$ Tween-20 (PBST). After the addition of $1 \%$ BSA and $5 \%$ sucrose $(300 \mu \mathrm{l} /$ well), the plate was incubated for $2 \mathrm{~h}$ at room temperature and again washed 3 times with PBST. The standards and samples were pipetted at $100 \mu \mathrm{l}$ per well and allowed to incubate for $2 \mathrm{~h}$ at room temperature, then washed 3 times with PBST. After removing the entire buffer from the wash, $100 \mu l$ of detection antibody ( $25 \mathrm{ng} / \mathrm{ml}$ in diluent) was added to each well. This was incubated for $2 \mathrm{~h}$ at room temperature and then washed 3 times with PBST. Then, $100 \mu$ l of diluted streptavidin-conjugated horse- 
Table 1. Demographic and clinical characteristics of the subjects

\begin{tabular}{|c|c|c|c|c|c|c|}
\hline & \multirow{2}{*}{$\begin{array}{l}\text { Control subjects } \\
(\mathrm{n}=50)\end{array}$} & \multicolumn{3}{|c|}{ Depressive patients $(n=32)$} & \multirow{2}{*}{$\begin{array}{l}\mathrm{p} \text { values } \\
\text { (control } \\
\text { vs. all) }\end{array}$} & \multirow{2}{*}{$\begin{array}{l}\text { p values } \\
\text { (responders } \\
\text { vs. non-re- } \\
\text { sponders) }\end{array}$} \\
\hline & & $\begin{array}{l}\text { all } \\
(n=32)\end{array}$ & $\begin{array}{l}\text { responders } \\
(\mathrm{n}=24)\end{array}$ & $\begin{array}{l}\text { non-responders } \\
(\mathrm{n}=8)\end{array}$ & & \\
\hline Age, years & $38.5 \pm 9.7$ & $44.2 \pm 17.3$ & $46.6 \pm 16.7$ & $36.6 \pm 17.6$ & $0.57^{\mathrm{a}}$ & $0.16^{\mathrm{b}}$ \\
\hline \multicolumn{7}{|l|}{ Sex, n } \\
\hline Male & 24 & 11 & 8 & 3 & $0.22^{\mathrm{d}}$ & $0.83^{\mathrm{e}}$ \\
\hline Female & 26 & 21 & 16 & 5 & & \\
\hline Weight, kg & $58.8 \pm 11.1$ & $55.7 \pm 11.0$ & $53.9 \pm 11.5$ & $61.6 \pm 6.0$ & $0.25^{\mathrm{a}}$ & $0.13^{\mathrm{b}}$ \\
\hline Body mass index & $22.1 \pm 2.9$ & $22.3 \pm 3.9$ & $21.5 \pm 4.1$ & $23.7 \pm 3.3$ & $0.87^{\mathrm{a}}$ & $0.26^{\mathrm{b}}$ \\
\hline Age at onset, years & $\mathrm{n} / \mathrm{a}$ & $40.1 \pm 16.9$ & $42.6 \pm 15.7$ & $33.5 \pm 19.0$ & $\mathrm{n} / \mathrm{a}$ & 0.18 \\
\hline Duration of illness, months & $\mathrm{n} / \mathrm{a}$ & $46.2 \pm 85.9$ & $58.0 \pm 96.7$ & $10.3 \pm 9.7$ & $\mathrm{n} / \mathrm{a}$ & $0.25^{\mathrm{b}}$ \\
\hline Psychiatric hospitalizations, $\mathrm{n}$ & $\mathrm{n} / \mathrm{a}$ & $0.56 \pm 0.91$ & $0.62 \pm 0.88$ & $0.38 \pm 1.06$ & $\mathrm{n} / \mathrm{a}$ & $0.51^{\mathrm{b}}$ \\
\hline HDRS, baseline score & $\mathrm{n} / \mathrm{a}$ & $29.6 \pm 8.4^{c}$ & $29.4 \pm 8.6$ & $29.9 \pm 7.9$ & $\mathrm{n} / \mathrm{a}$ & $0.90^{\mathrm{b}}$ \\
\hline HDRS, 6-week score & $\mathrm{n} / \mathrm{a}$ & $8.8 \pm 8.0^{c}$ & $5.0 \pm 4.1$ & $20.3 \pm 5.2$ & $\mathrm{n} / \mathrm{a}$ & $<0.01^{\mathrm{b}}$ \\
\hline Plasma BDNF (baseline), pg/ml & $830.7 \pm 624.8$ & $698.1 \pm 537.7$ & $733.0 \pm 512.2$ & $593.5 \pm 634.0$ & $0.33^{\mathrm{a}}$ & $0.50^{\mathrm{b}}$ \\
\hline
\end{tabular}

Values presented as means \pm SD. $\mathrm{n} / \mathrm{a}=$ Not applicable.

${ }^{\mathrm{a}}$ Independent samples $\mathrm{t}$ test; ${ }^{\mathrm{b}}$ Mann-Whitney test; ${ }^{\mathrm{c}}$ Paired samples $\mathrm{t}$ test $(\mathrm{p}<0.01) ;{ }^{\mathrm{d}} \chi^{2}$ test; ${ }^{\mathrm{e}}$ Fisher's exact test.

radish peroxidase was added to each well, incubated for $20 \mathrm{~min}$ at room temperature, and washed 3 times with PBST. Following the final washing procedure, $100 \mu \mathrm{l}$ of substrate solution (R\&D systems, cat No. DY999) was added to each well and then incubated for $20 \mathrm{~min}$ at room temperature. The reaction was terminated with $50 \mu \mathrm{l}$ of $2 \mathrm{~N}$ sulfuric acid. The optical density of the color reaction in the wells was read using a microtiter plate reader (BioTek Instruments) set for $450 \mathrm{~nm}$. The intra- and interassay coefficients of variation were below $10 \%$. The concentrations of the samples in each plate were calculated according to a standard curve.

\section{Statistical Analysis}

All statistical analyses were performed with SPSS version 12.01 for Windows. The Pearson $\chi^{2}$ test was used for testing the categorical variables, such as sex or diagnosis. Group mean differences were ascertained by means of Student's $t$ test, paired $t$ test, and Mann-Whitney test. The Wilcoxon signed-ranks test was used to compare the BDNF levels before and after antidepressant administration in the non-responder group. Statistical significance was accepted if the two-tailed probability was less than 0.05 .

\section{Results}

\section{Characteristics of the Subjects}

Table 1 shows the demographic and clinical characteristics of both depressive patients and control subjects. There were no statistically significant differences between depressive patients and control subjects with respect to age $(\mathrm{p}=0.57)$, gender $(\mathrm{p}=0.21)$, weight $(\mathrm{p}=0.25)$, or BMI ( $\mathrm{p}=0.87)$. At 6 weeks after treatment, there was a significant decrease in the HDRS scores from baseline in the depressive patients, and 24 subjects were placed in the responder group and 8 in the non-responder group. Regarding age, gender, age of onset, duration of illness, number of psychiatric hospitalizations, and baseline HDRS score, there were no significant differences between the responder and non-responder groups.

\section{Comparison of Plasma BDNF Levels between \\ Depressive Patients and Control Subjects}

At baseline, the mean plasma BDNF level was lower in depressive patients $(698.1 \pm 537.7 \mathrm{pg} / \mathrm{ml})$ than in the control subjects $(830.7 \pm 624.8 \mathrm{pg} / \mathrm{ml})$, but the difference was not statistically significant $(\mathrm{p}=0.33)$. Baseline plasma BDNF levels in non-responders were not significantly lower than those of controls in the present study ( $\mathrm{p}=$ $0.20)$.

\section{Comparison of Plasma BDNF Levels after 6 Weeks of Antidepressant Treatment}

The plasma BDNF levels in depressive patients significantly increased from $698.1 \pm 537.7$ to $1,028.9 \pm 744.5$ after 6 weeks of antidepressant treatment $(\mathrm{p}=0.01$, data not shown). Moreover, in the responder group, plasma BDNF levels had increased from $733.0 \pm 512.2$ to $1,153.6$ $\pm 766.0 \mathrm{pg} / \mathrm{ml}$ after antidepressant treatment $(\mathrm{p}<0.01$; fig. 1). There was, however, no significant change after 


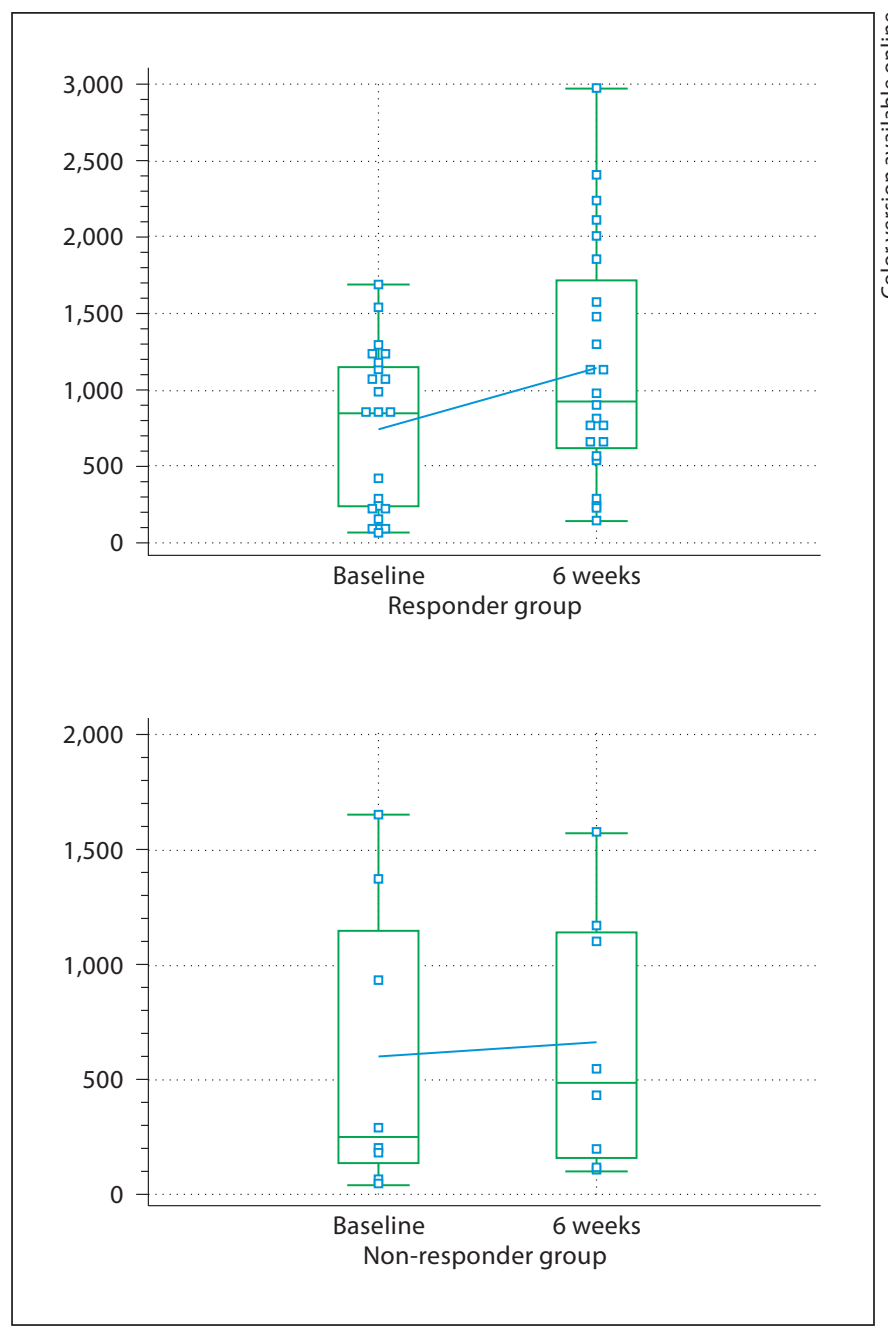

Fig. 1. Changes in plasma BDNF levels after antidepressant treatment in the responder and non-responder groups. At baseline, there was a significant difference in plasma BDNF levels between the responder group $(733.0 \pm 512.2 \mathrm{pg} / \mathrm{ml})$ and the non-responder group $(593.5 \pm 634.0 \mathrm{pg} / \mathrm{ml} ; \mathrm{p}=0.50)$. After 6 weeks of treatment, plasma BDNF levels had increased from $733.0 \pm 512.2$ to $1,153.6 \pm 766.0 \mathrm{pg} / \mathrm{ml}$ in the responder group $(\mathrm{p}<0.01)$. There was, however, no significant change after antidepressant treatment in the non-responder group (from $593.5 \pm 634.0$ to 654.7 $\pm 559.8 \mathrm{pg} / \mathrm{ml} ; \mathrm{p}=0.83$ ). After 6 weeks of treatment, a stronger tendency for plasma BDNF levels to increase was shown in the responder group $(1,153.6 \pm 766.0 \mathrm{pg} / \mathrm{ml})$ compared to the nonresponder group $(654.7 \pm 559.8 \mathrm{pg} / \mathrm{ml} ; \mathrm{p}=0.08)$.

antidepressant treatment in the non-responder group (from $593.5 \pm 634.0$ to $654.7 \pm 559.8 \mathrm{pg} / \mathrm{ml}, \mathrm{p}=0.83$ fig. 1). After 6 weeks of treatment, a stronger tendency for plasma BDNF levels to increase was shown in the responder group $(1,153.6 \pm 766.0 \mathrm{pg} / \mathrm{ml})$ compared to the non-responder group $(654.7 \pm 559.8 \mathrm{pg} / \mathrm{ml} ; \mathrm{p}=0.08)$.

\section{Discussion}

We demonstrated that plasma BDNF levels increased significantly in depressive patients after antidepressant administration. Moreover, the increase in plasma BDNF levels was found in the responder group but not in the non-responder group. In a human post-mortem study, increased BDNF expression in hippocampal tissue was observed in antidepressant-treated depressive patients [13]. Similarly, pre-clinical studies have demonstrated that BDNF is associated with antidepressant treatment $[12,14,22]$. In clinical studies, Shimizu et al. [23] demonstrated that serum BDNF levels were significantly lower in an antidepressant-naïve depressive group than in either an antidepressant-treated depressive group or a control group. Because the antidepressant-naïve and antidepressant-treated patients were not the same subjects in that study [23], however, it was not possible to compare BDNF levels at baseline with levels after antidepressant administration. Aydemir et al. [24] showed that treatment for 12 weeks with venlafaxine, a serotonin-norepinephrine reuptake inhibitor (SNRI), significantly increased serum BDNF levels in patients with a major depressive disorder. In this study, BDNF levels in the treated patients improved to the levels detected in control subjects. It was also reported that treatment with $10 \mathrm{mg} /$ day of S-citalopram, a selective serotonin reuptake inhibitor (SSRI), for 6 weeks significantly increased serum BDNF levels in patients with a major depressive disorder [25]. After SSRI or SNRI administration, serum BDNF levels in depressed patients are significantly increased $[26,27]$. In addition, Gonul et al. [27] reported that no difference was seen in the serum BDNF levels of patients receiving SSRI or venlafaxine, a SNRI. In a study restricted to female patients, the post-treatment BDNF levels of depressive patients were significantly higher than the pre-treatment levels after 6 weeks of treatment and were similar to the levels seen in control subjects $[25,28]$. Yoshimura et al. [29] reported that patients responding to treatment with paroxetine (an SSRI) and milnacipran (an SNRI) for 8 weeks saw serum BDNF levels significantly increase to the same levels as the control group, but serum BDNF levels in non-responders did not increase. This finding is in agreement with the present study, suggesting that BDNF may be regarded as a peripheral marker for the action mechanism of antidepressant drugs [30]. Based on the neuroplasticity theory, BDNF is important to maintaining synaptic function and neural plasticity. In the presence of impaired neural plasticity, depression occurs. Antidepressant drugs may reverse depression due to 
their ability to activate genes that encode neurotrophic factors [31, 32].

In accordance with previous studies [23-27, 33], baseline plasma BDNF levels were lower in the depressive patients than in normal controls, although there was no statistical significance in this study. The possible reasons for non-significance are as follows. First, the greater body weight of normal controls compared to depressive patients could contribute to non-significance because BDNF levels in plasma decrease with increasing weight [34]. Second, a greater proportion of females in the depressive patients could be a cause of non-significance due to changes in BDNF levels during the menstrual cycle [34]. Third, the small sample size and a high variance of plasma BDNF levels could be a major cause of the non-significance.

We tested the possibility of using BDNF plasma levels as a prodromic marker of non-response by comparing the BDNF plasma levels of the non-responder group to those of the controls. Baseline BDNF plasma levels of non-responders were not significantly lower than those of the controls in the present study $(\mathrm{p}=0.20)$. The lack of significant differences in baseline BDNF plasma levels between non-responders and controls suggests that baseline BDNF levels might not be a prodromic marker of non-response.

The fact that the relation between plasma and brain BDNF levels is not very clear should also be noted. A major limitation of studies of plasma is that it is difficult to determine the significance of BDNF that is outside the blood-brain barrier. Most BDNF in the blood is stored in platelets [35], and one physiological study reported the free passage of intact BDNF across the blood-brain barrier by a high-capacity and saturable transport system as well as the efflux of BDNF from the brain to the blood [36]. Several studies have observed a positive correlation between serum and cortical levels of BDNF, indicating that the peripheral measurement of BDNF could be used as a surrogate measure for BDNF levels in the central nervous system $[33,37]$. There is a large amount of evidence that other peripheral growth factors influence central nervous system function [38, 39]. Piccinni et al. [40] reported that, while the plasma BDNF levels increased to the values found in control subjects in parallel with the clinical improvement, antidepressant treatments did not induce any change in serum BDNF levels, which remained lower than those found in the control group at all assessment times (1st, 3rd, 6th, 12th month). Thereafter, they suggest, while plasma BDNF would behave as a statedependent marker, serum BDNF might represent a trait of illness. Similarly, considering the interactions among plasma, platelets, and the blood-brain barrier [34-36], plasma BDNF levels may reflect brain BDNF levels.

Some other limitations of this study are as follows. First, due to the lack of a placebo group, we could not exclude the changes in BDNF levels that occurred in the course of illness. It is not possible to know to what degree the responses of the responders were due to the placebo effect versus pure antidepressant effect. Second, the present study had a very small sample size and included 3 suicidal subjects ( 2 drug intoxications and 1 deep laceration in the wrist). Suicide attempts can induce confounding effects [41]. Third, various kinds of antidepressants (SSRI, SNRI) were used in unblinded conditions, thus, creating heterogenous treatment exposures. Therefore, the effects of different antidepressants on BDNF levels should be considered. There have been some inconsistent reports with respect to certain classes of antidepressants $[19,20]$. Many studies, however, show no difference between the BDNF levels of patients receiving SSRI or SNRI $[27,29]$. Moreover, although antidepressants are classified on the basis of their immediate actions on neurotransmitter receptors and enzymes, attention is increasingly being focused on how these immediate actions translate into delayed actions [31].

In conclusion, these results suggest that the therapeutic response after antidepressant administration is possibly related to the increase in BDNF levels, consistent with the neuroplasticity hypothesis. Given the complexity of both the physiological and pharmacological regulation of BDNF, it may be too simplistic to hypothesize that we would be able to identify the role of BDNF in the mechanism of action of antidepressant agents by examining the changes in plasma BDNF levels before and after antidepressant administration. Therefore, this study suggests a possible association between changes in BDNF levels and the therapeutic response to treatment. Further studies investigating the reason that BDNF levels are not increased after antidepressant administration in some patients, and more controlled studies with a larger number of subjects, may help to improve the rate of response to antidepressant therapy.

\section{Acknowledgement}

This study was supported by a grant from Korea University. 


\section{References}

1 Lewin GR, Barde YA: Physiology of the neurotrophins. Annu Rev Neurosci 1996;19: 289-317.

-2 Smith MA, Makino S, Kvetnansky R, Post RM: Stress and glucocorticoids affect the expression of brain-derived neurotrophic factor and neurotrophin-3 mRNAs in the hippocampus. J Neurosci 1995;15:1768-1777.

-3 Nibuya M, Takahashi M, Russell DS, Duman RS: Repeated stress increases catalytic TrkB mRNA in rat hippocampus. Neurosci Lett 1999;267:81-84.

4 Gould E, McEwen BS, Tanapat P, Galea LA, Fuchs E: Neurogenesis in the dentate gyrus of the adult tree shrew is regulated by psychosocial stress and NMDA receptor activation. J Neurosci 1997;17:2492-2498.

5 Gould E, Tanapat P, McEwen BS, Flugge G, Fuchs E: Proliferation of granule cell precursors in the dentate gyrus of adult monkeys is diminished by stress. Proc Natl Acad Sci USA 1998;95:3168-3171.

6 Magarinos AM, McEwen BS: Stress-induced atrophy of apical dendrites of hippocampal CA3c neurons: involvement of glucocorticoid secretion and excitatory amino acid receptors. Neuroscience 1995;69:89-98.

7 Durany N, Michel T, Kurt J, Cruz-Sanchez FF, Cervas-Navarro J, Riederer P: Brain-derived neurotrophic factor and neurotrophin3 levels in Alzheimer's disease brains. Int J Dev Neurosci 2000;18:807-813.

8 Takahashi M, Shirakawa O, Toyooka K, Kitamura N, Hashimoto T, Maeda K, Koizumi S, Wakabayashi K, Takahashi H, Someya T, Nawa H: Abnormal expression of brain-derived neurotrophic factor and its receptor in the corticolimbic system of schizophrenic patients. Mol Psychiatry 2000;5: 293-300.

$\checkmark 9$ Shoval G, Weizman A: The possible role of neurotrophins in the pathogenesis and therapy of schizophrenia. Eur Neuropsychopharmacol 2005;15:319-329.

$\checkmark 10$ Duman RS, Heninger GR, Nestler EJ: A molecular and cellular theory of depression. Arch Gen Psychiatry 1997;54:597-606.

-11 Altar CA: Neurotrophins and depression. Trends Pharmacol Sci 1999;20:59-61.

-12 Siuciak JA, Lewis DR, Wiegand SJ, Lindsay RM: Antidepressant-like effect of brain-derived neurotrophic factor (BDNF). Pharmacol Biochem Behav 1997;56:131-137.

13 Chen B, Dowlatshahi D, MacQueen GM, Wang JF, Young LT: Increased hippocampal BDNF immunoreactivity in subjects treated with antidepressant medication. Biol Psychiatry 2001;50:260-265.

- 14 Nibuya M, Morinobu S, Duman RS: Regulation of BDNF and TrkB mRNA in rat brain by chronic electroconvulsive seizure and antidepressant drug treatments. J Neurosci 1995; 15:7539-7547.
15 Hindmarch I: Expanding the horizons of depression: beyond the monoamine hypothesis. Hum Psychopharmacol 2001;16:203218.

16 NemeroffCB: Psychopharmacology of affective disorders in the 21st century. Biol Psychiatry 1998;44:517-525.

17 Duman RS, Malberg J, Nakagawa S, D’Sa C: Neuronal plasticity and survival in mood disorders. Biol Psychiatry 2000;48:732-739.

18 Popoli M, Gennarelli M, Racagni G: Modulation of synaptic plasticity by stress and antidepressants. Bipolar Dis 2002;4:166-182.

19 Duman RS, Monteggia LM: A neurotrophic model for stress-related mood disorders. Biol Psychiatry 2006;59:1116-1127.

-20 Tardito D, Perez J, Tiraboschi E, Musazzi L, Racagni G, Popoli M: Signaling pathways regulating gene expression, neuroplasticity, and neurotrophic mechanisms in the action of antidepressants: a critical overview. Pharmacol Rev 2006;58:115-134.

21 Hamilton M: A rating scale for depression. J Neurol Neurosurg Psychiatry 1960;23:5662.

22 Nibuya M, Nestler EJ, Duman RS: Chronic antidepressant administration increases the expression of camp response element binding protein (CREB) in rat hippocampus. J Neurosci 1996;16:2365-2372.

-23 Shimizu E, Hashimoto K, Okamura N, Koike K, Komatsu N, Kumakiri C, Nakazato M, Watanabe H, Shinoda N, Okada S, Iyo M: Alterations of serum levels of brain-derived neurotrophic factor (BDNF) in depressed patients with or without antidepressants. Biol Psychiatry 2003;54:70-75.

24 Aydemir O, Deveci A, Taneli F: The effect of chronic antidepressant treatment on serum brain-derived neurotrophic factor levels in depressed patients: a preliminary study. Prog Neuropsychopharmacol Biol Psychiatry 2005;29:261-265.

-25 Aydemir C, Yalcin ES, Aksaray S, Kisa C, Yildirim SG, Uzbay T, Goka E: Brain-derived neurotrophic factor (BDNF) changes in the serum of depressed women. Prog Neuropsychopharmacol Biol Psychiatry 2006;30: 1256-1260.

26 Gervasoni N, Aubry JM, Bondolfi G, Osiek C, Schwald M, Bertschy G, Karege F: Partial normalization of serum brain-derived neurotrophic factor in remitted patients after a major depressive episode. Neuropsychobiology 2005;51:234-238.

27 Gonul AS, Akdeniz F, Taneli F, Donat O, Eker C, Vahip S: Effect of treatment on serum brain-derived neurotrophic factor levels in depressed patients. Eur Arch Psychiatry Clin Neurosci 2005;255:381-386.

28 Huang TL, Lee CT, Liu YL: Serum brain-derived neurotrophic factor levels in patients with major depression: effects of antidepressants. J Psychiatr Res 2008;42:521-525.
-29 Yoshimura R, Mitoma M, Sugita A, Hori H, Okamoto T, Umene W, Ueda N, Nakamura $\mathrm{J}$ : Effects of paroxetine or milnacipran on serum brain-derived neurotrophic factor in depressed patients. Prog Neuropsychopharmacol Biol Psychiatry 2007;31:1034-1037.

-30 D'Sa C, Duman RS: Antidepressants and neuroplasticity. Bipolar Dis 2002;4:183-194.

-31 Stahl SM: Blue genes and the mechanism of action of antidepressants. J Clin Psychiatry 2000;61:164-165.

$>32$ Stahl SM: Blue genes and the monoamine hypothesis of depression. J Clin Psychiatry 2000;61:77-78.

33 Karege F, Perret G, Bondolfi G, Schwald M, Bertschy G, Aubry JM: Decreased serum brain-derived neurotrophic factor levels in major depressed patients. Psychiatry Res 2002;109:143-148.

34 Lommatzsch M, Zingler D, Schuhbaeck K, Schloetcke K, Zingler C, Schuff-Werner P, Virchow JC: The impact of age, weight and gender on BDNF levels in human platelets and plasma. Neurobiol Aging 2005;26:115123.

35 Fujimura H, Altar CA, Chen R, Nakamura T, Nakahashi T, Kambayashi J, Sun B, Tandon $\mathrm{NN}$ : Brain-derived neurotrophic factor is stored in human platelets and released by agonist stimulation. Thromb Haemost 2002; 87:728-734.

36 Pan W, Banks WA, Fasold MB, Bluth J, Kastin AJ: Transport of brain-derived neurotrophic factor across the blood-brain barrier. Neuropharmacology 1998;37:1553-1561.

37 Karege F, Schwald M, Cisse M: Postnatal developmental profile of brain-derived neurotrophic factor in rat brain and platelets. Neurosci Lett 2002;328:261-264.

38 Trejo JL, Carro E, Torres-Aleman I: Circulating insulin-like growth factor I mediates exercise-induced increases in the number of new neurons in the adult hippocampus. J Neurosci 2001;21:1628-1634.

-39 Fabel K, Tam B, Kaufer D, Baiker A, Simmons N, Kuo CJ, Palmer TD: VEGF is necessary for exercise-induced adult hippocampal neurogenesis. Eur J Neurosci 2003;18:28032812.

40 Piccinni A, Marazziti D, Catena M, Domenici L, Del Debbio A, Bianchi C, Mannari C, Martini C, Da Pozzo E, Schiavi E, Mariotti A, Roncaglia I, Palla A, Consoli G, Giovannini L, Massimetti G, Dell'Osso L: Plasma and serum brain-derived neurotrophic factor (BDNF) in depressed patients during 1 year of antidepressant treatments. J Affect Disord 2008;105:279-283.

$>41$ Kim YK, Lee HP, Won SD, Park EY, Lee HY, Lee BH, Lee SW, Yoon D, Han C, Kim DJ, Choi SH: Low plasma BDNF is associated with suicidal behavior in major depression. Prog Neuropsychopharmacol Biol Psychiatry 2007;31:78-85. 